\title{
Reduction of pattern effects in SOA-based all-optical switches by using cross-gain modulated holding signal
}

Bischoff, Svend; Mørk, Jesper

Published in:

Summaries of Papers Presented at the Lasers and Electro-Optics, 2002. CLEO '02. Technical Digest.

Link to article, DOI:

10.1109/CLEO.2002.1034076

Publication date:

2002

Document Version

Publisher's PDF, also known as Version of record

Link back to DTU Orbit

Citation (APA):

Bischoff, S., \& Mørk, J. (2002). Reduction of pattern effects in SOA-based all-optical switches by using crossgain modulated holding signal. In Summaries of Papers Presented at the Lasers and Electro-Optics, 2002. CLEO '02. Technical Digest. (Vol. 1). IEEE. https://doi.org/10.1109/CLEO.2002.1034076

\section{General rights}

Copyright and moral rights for the publications made accessible in the public portal are retained by the authors and/or other copyright owners and it is a condition of accessing publications that users recognise and abide by the legal requirements associated with these rights.

- Users may download and print one copy of any publication from the public portal for the purpose of private study or research.

- You may not further distribute the material or use it for any profit-making activity or commercial gain

- You may freely distribute the URL identifying the publication in the public portal 
delayed interference configuration," Electron. Lett., 36, 1129-1130 (2000).

CWA53 1:00 pm

Reduction of Pattern Effects in SOA-based All-optical Switches by Using Cross-gain Modulated Holding Signal

Svend Bischoff and Jesper Mork, Research Center COM, Build. 345 w, The Technical University of Denmark, DK-2800 Kgs. Lyngby, Denmark, Email: sb@com.dtu.dk

All-optical signal processing is interesting for increasing the bit rate to $40 \mathrm{Gbit} / \mathrm{s}$ and beyond. So far, error free demultiplexing of a $252 \mathrm{Gbit} / \mathrm{s}$ signal to the base rate of $\mathbf{1 0 . 5}$ has been experimentally demonstrated in an SOA based symmetric Mach-Zehnder Interferometer (MZI). ${ }^{1}$ Wavelength Conversion (WC) of a $168 \mathrm{Gbit} / \mathrm{s}$ signa has been demonstrated in a delayed interference semiconductor wavelength converter. ${ }^{2}$ In the latter case, the PRBS sequence was limited to $2^{7}-1$ to obtain error-free WC. This limitation was ascribed to patterning effects due to the carrier-lifetime limited recovery process. The effective carrier lifetime of SOAs is typically shortened by an intense Continuous Wave (CW) holding signal. ${ }^{3}$ However, the SOA gain is reduced by the holding signal resulting in smaller gain and refractive index changes induced by the data signal. Accordingly an optimum exists for the $\mathrm{CW}$ and data signal power. Here, we demonstrate that the modulation bandwidth (amplitude jitter) is significantly improved (reduced) by replacing the CW holding beam with a signal, which is lowpass filtered and inverted with respect to the data signal. Such a holding beam can be generated by XGM WC in an SOA, and reduces the fluctuations of the total energy injected into the interferometer within a bit-slot.

Fig. 1 shows a schematic of differential WC in an MZI. The signals on the left hand side are the data and delayed data signal, the XGM holding signal, which is replacing the CW holding signal, and a weak CW signal onto which the data pattern is transferred. The right hand side of Fig. 1 shows the wavelength converted optical eye $\left(\lambda_{c w}\right)$. The MZI parameter values have been optimized such that clear and open eyes are observed simultaneously for both inverted and non-inverted WC. The MZI was simulated with $500 \mu \mathrm{m}$ long bulk SOAs; other parameter values and a description of our large signal model can be found in. ${ }^{4}$

Figs. 2.a-d show optical eyes corresponding to four different holding beams. A fraction of the

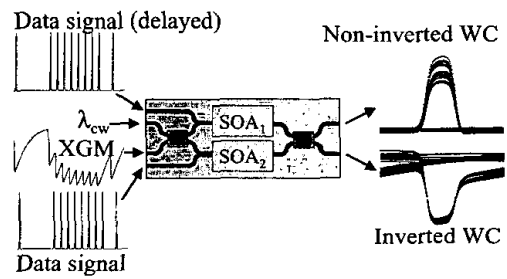

CWA53 Fig. 1. Schematic of the simulated MZI setup. The data, holding and CW signal are shown on the left hand side. Inverted and non-inverted optical eyes after Wavelength Conversion (WC) are shown on the right hand side.
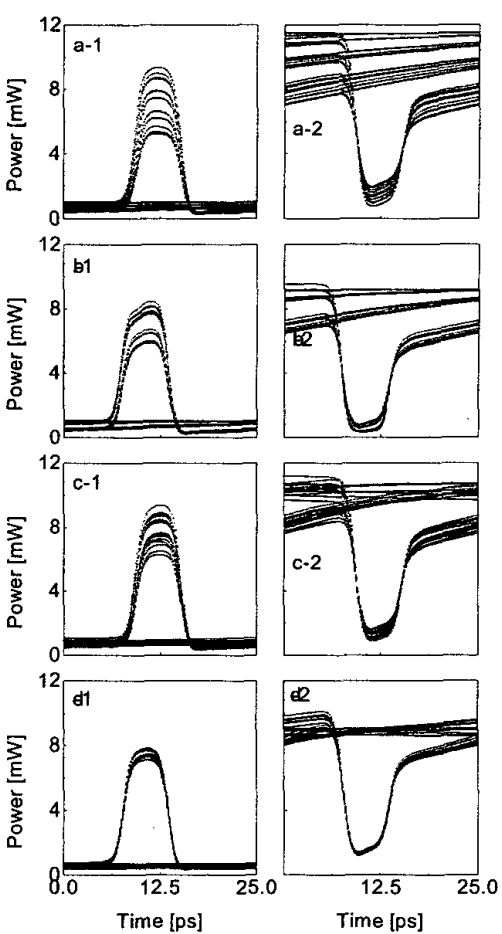

CWA53 Fig. 2. Optical eyes for non-inverted (column 1) and inverted (column 2) WC for identical MZI operation conditions, where only the data signal power and the holding signal have been varied. $A$ fraction of the holding and data signal in Figs. a-d is shown in Figs. 3 a-d, respectively.

time sequence of the data and holding signal corresponding to Figs. 2.a-d is shown in Figs. 3a-d. The different holding signals $\mathrm{b}-\mathrm{d}$ correspond to different integration time constants of the XGM holding signal.

Fig. 2.a shows that WC at $40 \mathrm{Gbit} / \mathrm{s}$ for the chosen SOA parameter values result in strong amplitude jitter in case of a CW holding signal. In Figs. 2.b-d the three different XGM holding beams all result in a reduced amplitude jitter after WC compared to the case with a CW holding signal, even though Fig. 2.d indicates that a larger modulation depth in the XGM holding signals of Figs. 2.b and 2.c would result in a slightly better amplitude jitter reduction. Thus, the average holding signal power, the modulation depth and the time-delay between data signal and XGM holding signal have some influence on the amount of amplitude jitter reduction and should be optimized.

In conclusion, a method is presented for reducing pattern effects in SOAs by employing a partially inverted holding beam. The method should be useful for increasing the data rates of all-optical switches.

1. S. Nakamura, Y. Ueno, J. Sasaki, K. Tajima, "Error-free demultiplexing at $252 \mathrm{Gbit} / \mathrm{s}$ and low-power-penalty, jitter-tolerant demultiplexing at $168 \mathrm{Gbit} / \mathrm{s}$ with integrated symmetric Mach-Zehnder all optical switch", ECOC' 01 , paper Th.F.2.2, Eur. Conf. on Opt. Commo., Amsterdam (2001).
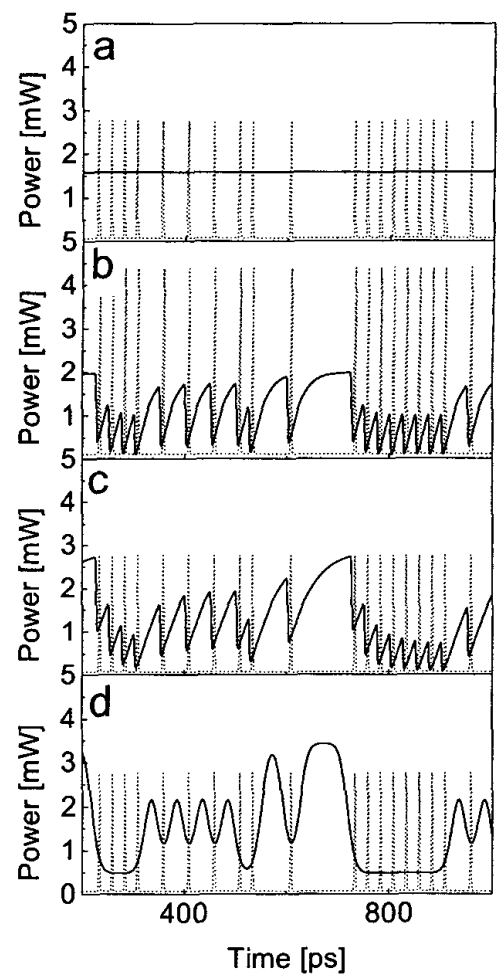

CWA53 Fig. 3. shows a fraction of the time sequence of the data (divided by 20 , dotted) and holding signal (solid) used in Figs. 2.a-d, respectively. The holding signals in Figs. $b$ and $d$ are generated with an integration time constant of 20 and 40 ps, respectively. The holding signal in Fig. $c$ is generated by assuming an instantaneous material response, but with the data signal pulses for the generation of the inverted signal having a width of $25 \mathrm{ps}$.

2. S. Nakamura, Y. Ueno, K. Tajima, " $168-G b / s$ all-optical wavelength conversion with a symmetric-Mach-Zehnder-Type switch", IEEE Photon. Technol. Lett. 13 (10), 10911093 (2001).

3. R.J. Manning, A.D. Ellis, A.J. Poustie, K.J. Blow, "Semiconductor laser amplifiers for ultrafast sll-optical signal processing”, J. Opt. Soc. Am B 14 (11), 3204-3216 (1997).

4. S. Bischoff, A. Buxens, St. Fischer, M. Dülk, A.T. Clausen, H.N. Poulsen, J. Mørk, "Comparison of all-optical co- and counter-propagating high-speed signal processing in SOA-based Mach-Zehnder interferometers", Optical and Quantum Electronics 33, 907926 (2001).

CWA54 1:00 pm

Group Velocity Dispersion Using Commercial Optical Design Programs

Donald C. O'Shea, School of Physics, Georgia Institute of Technology, Atlanta, GA 30332-0430 USA, Email: doshea@prism.gatech.edu

Most analyses of the group velocity dispersion (GVD) of the ultrafast geometries used in pulse 